\title{
Health Benefits of Ganoderma lucidum as a Medicinal Mushroom ${ }^{\#}$
}

\author{
Sanem Bulam ${ }^{1, a, *}$, Nebahat Şule Üstünn, ${ }^{2, b}$ Aysun Pekşen ${ }^{3, c}$ \\ ${ }^{1}$ Department of Food Engineering, Faculty of Engineering, Giresun University, Güre Campus, 28200 Giresun/Turkey \\ ${ }^{2}$ Department of Food Engineering, Faculty of Engineering, Ondokuz Mayls University, Kurupelit Campus, 55139 Atakum/Samsun, Turkey. \\ ${ }^{3}$ Department of Horticulture, Faculty of Agriculture, Ondokuz Mayls University, Kurupelit Campus, 55139 Atakum/Samsun, Turkey. \\ *Corresponding author
}

\begin{tabular}{|c|c|}
\hline A R T ICLE INFO & A B S T R A C T \\
\hline $\begin{array}{l}\text { Keywords: } \\
\text { Clinical trials } \\
\text { Ganoderma lucidum } \\
\text { Medicinal } \\
\text { Pharmacological } \\
\text { Bioactive compound }\end{array}$ & $\begin{array}{l}\text { Ganoderma lucidum (Curtis) P. Karst., known as "Lingzhi" in China or "Reishi" in Japan, is a well- } \\
\text { known medicinal mushroom and traditional Chinese medicine, which has been used for the } \\
\text { prevention and treatment of bronchitis, allergies, hepatitis, immunological disorders and cancer. } G \text {. } \\
\text { lucidum is rarely collected from nature and mostly cultivated on wood logs and sawdust in plastic } \\
\text { bags or bottles to meet the demands of international markets. Diverse groups of chemical } \\
\text { compounds with pharmacological activities, isolated from the mycelia and fruiting bodies of } G \text {. } \\
\text { lucidum are triterpenoids, polysaccharides ( } \beta \text {-D-glucans), proteins, amino acids, nucleosides, } \\
\text { alkaloids, steroids, lactones, lectins, fatty acids, and enzymes. The biologically active compounds } \\
\text { as primarily triterpenoids and polysaccharides of } G \text {. lucidum have been reported to possess } \\
\text { hepatoprotective, antihypertensive, hypocholesterolemic, antihistaminic effects and antioxidant, } \\
\text { antitumor, immunomodulatory, and antiangiogenic activities. Several formulations have been } \\
\text { developed, patented and used as nutraceuticals, nutriceuticals and pharmaceuticals from } G \text {. } \\
\text { lucidum's water or ethanol extracts and rarely purified active compounds. As the result of clinical } \\
\text { trials, various products have commercially become available as syrup, injection, tablet, tincture or } \\
\text { bolus of powdered medicine and an ingredient or additive in dark chocolate bars and organic } \\
\text { fermented medicinal mushroom drink mixes such as green teas, coffees, and hot cacaos. This review } \\
\text { has intended to give and discuss recent knowledge on phytochemical and pharmacological } \\
\text { compositions, therapeutic and side effects, clinical trials, and commercial products of G. lucidum. }\end{array}$ \\
\hline
\end{tabular}

Türk Tarım - Gıda Bilim ve Teknoloji Dergisi 7(sp1): 84-93, 2019

\section{Tıbbi Mantar Olarak Ganoderma lucidum'un Sağlık Üzerine Faydaları}

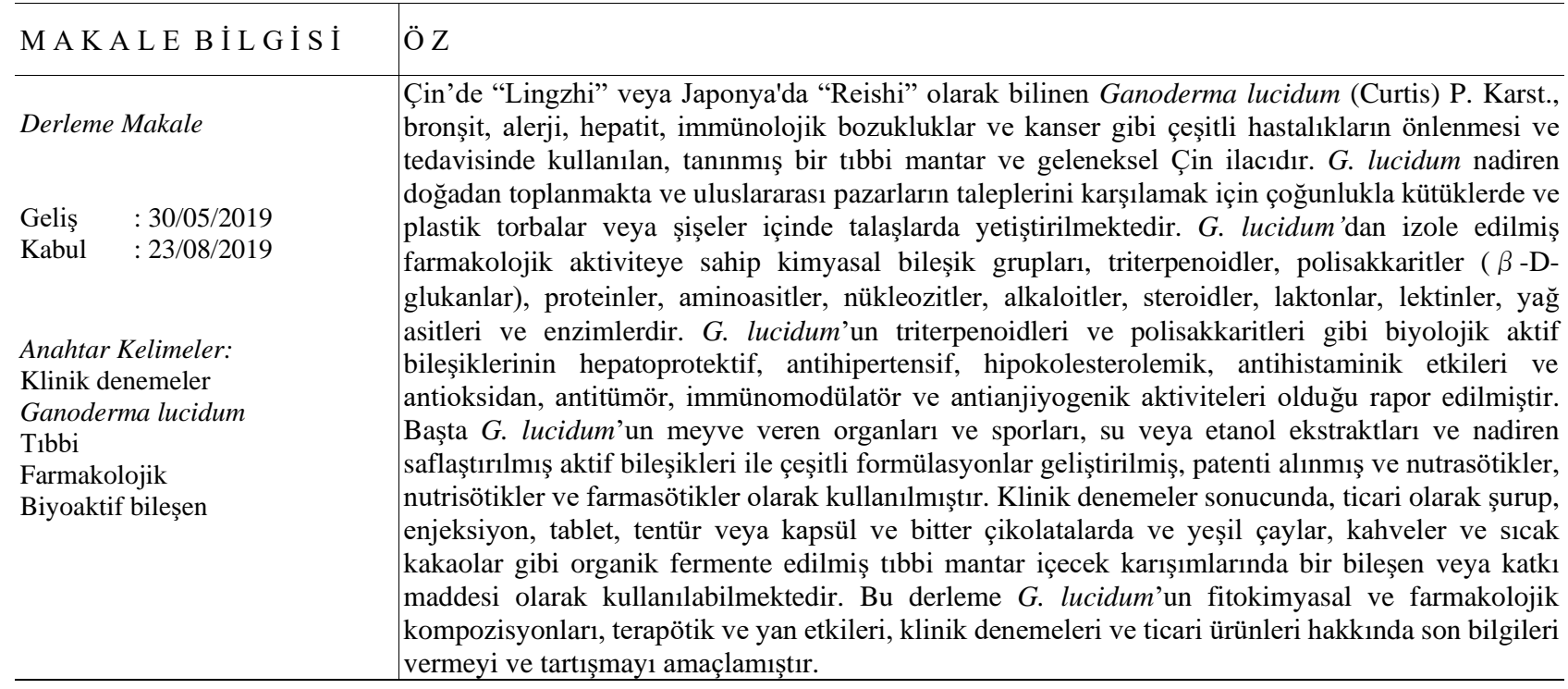




\section{Introduction}

Ganoderma lucidum (Curtis) P. Karst., also known as Ling Zhi, Reishi, Mannentake is a medicinal, wooddegrading basidiomycete with numerous pharmacological effects in addition to its key role in the environment as decomposer in nutrient cycle. G. lucidum is considered as "the king of herbs" which grows on the decaying and dead logs of deciduous trees like willow, oak, sweet gum, maple, elm and coniferous trees (larix, picea and pinus) (Khatian and Aslam, 2018; Sudheer et al., 2018). The most important pharmacologically active constituents of $G$. lucidum are triterpenoids and polysaccharides. Triterpenoids have been reported to possess hepatoprotective, anti-hypertensive, hypocholesterolemic and anti-histaminic effects, anti-tumor and anti-engiogenic activities, effects on platelet aggregation and complement inhibition. Polysaccharides, especially $\beta$-D-glucans, have been known to have anti-tumor effects through immunomodulation and anti-angiogenesis. In addition, polysaccharides have a protective effect against free radicals and reduce cell damage caused by mutagens. In general, G. lucidum triterpenes could directly suppress growth and invasive behaviour of cancer cells, whereas $G$. lucidum polysaccharides could synergistically stimulate the immune functions, resulting in the activation of anticancer activities of immune cells and production of cytokines (Paterson, 2006; Deepalakshmi and Mirunalini, 2011; Boh, 2013; Hapuarachchi et al., 2016a, b; Sohretoglu and Huang, 2018; Zhao et al., 2019). G. lucidum is distributed in green ecosystems both in tropical and temperate geographical regions in Asia, Africa, America and Europe (Wang et al., 2012b). It is also common in the mycobiota of Turkey (Sesli and Denchev, 2014).

G. lucidum is not classified as edible mushroom and not used in cooking because of its bitter taste and a wooden texture, however it is used in other various forms (Hapuarachchi et al., 2016a). In terms of ethnomedicinal knowledge, it has been widely used to promote health and longevity in Traditional Chinese Medicine as special teas or concoctions in China, Japan, and other Asian countries for over two millennia (Sudheer et al., 2018). It was both considered as the "herb of spiritual potency" or "plant of immortality" that extended the lifetime because of its medicinal properties by Chinese people and symbolized sanctity, success, goodness, happiness, fortune, immortality, and good health in these countries (Paterson, 2006; Sanodiya et al., 2009; Wachtel-Galor et al., 2011; De Silva et al., 2012; Hapuarachchi et al., 2018; Sudheer et al., 2018). It was first indexed in Shen Nong's Materia Medica (206 BC-8 AD), known as the "Father of Chinese medicine", as a longevity promoting and tonic herb of the non-toxic superior class (Zhu et al., 2007; Sharma et al., 2019). It is currently listed in the American Herbal Pharmacopoeia, Chinese Pharmacopoeia and Therapeutic Compendium (Wu et al., 2013). Today, this species is sold on the traditional local markets or supermarkets (Tibuhwa, 2018) and still used as medicine in traditional health care for the treatment of anthritis, neoplasia, cancer (alone or in combination with chemotherapy and radiotherapy), general disorders, genitourinary, dermatological, and respiratory systems, and in boosting the immune system by the indigenous people worldwide (Chang and Lee, 2004; Oyetayo, 2011; Valverde et al., 2015; Khastini et al., 2018; Tibuhwa, 2018).

Therapeutic administration has been realized as oral, topical application, and powder swallowing, cleaning wounds, tea extracts with other herbs, and tonics for long illness, and cancer treatment, and herbal soup with ginseng after drying. The most common preparation has been hot water extraction technique. Bioavailability of mushroom's active metabolite depends on the preparation technique (Khastini et al., 2018; Sudheer et al., 2018; Tibuhwa, 2018). Since the mushroom is very rare in the nature, fruiting bodies are artificially cultivated on wood logs and sawdust in plastic bags or bottles. G. lucidum can also be organically cultivated (Perumal, 2009). G. lucidum cultivation generally has at least three important contributions: production of health food, manufacture of nutraceuticals, and reduction of environmental pollution. Today, G. lucidum-based products have been generally divided into three types of products, including fruiting bodies, mycelia, and spore powder (Zhou et al., 2012; Hapuarachchi et al., 2018). G. lucidum mycelia, spores, and fruiting bodies-derived drugs, nutraceuticals, and dietary supplements as beverages, teas, powdered extracts, capsules, oral liquids, and chewable tablets (Hyde et al., 2010; Taofiq et al., 2016; Wu et al., 2016) are currently available and widely spread on the world market especially in China, Japan and North America (Lindequist et al., 2005; Deepalakshmi and Mirunalini, 2011; Boh, 2013; Rathore et al., 2017; Reis et al., 2017; Hapuarachchi et al., 2018; Khatian and Aslam, 2018; Sudheer et al., 2018; Zhao et al., 2019). In addition, various in vivo and clinical studies have shown that the extracts, spore preparations and dietary supplements of G. lucidum have no or little side effects (Boh, 2013; Hapuarachchi et al., 2016a, b; Khatian and Aslam, 2018; Sohretoglu and Huang, 2018; Sudheer et al., 2018; Zeng et al., 2018). Since there has been an increasing interest in G. lucidum, it was aimed to give recent knowledge on phytochemical and pharmacological compositions, therapeutic and side effects, clinical trials, and commercial products of this species in this review.

\section{Phytochemical, Pharmacological Composition and Therapeutic Properties of G. lucidum}

G. lucidum includes polysaccharides, flavonoids, and alkaloids, amino acids, steroids, oligosaccharides, proteins, mannitol, vitamins B1, B2, B6, choline, and inositol (Cör et al., 2018). The water content of this mushroom has been reported as $90 \%$ and its dry matter consists of $10-40 \%$ protein, 2-8\% fat, 3-28\% carbohydrate, 3-32\% fiber, 8$10 \%$ ash, minerals (Ca, P, K, Mg, Cu, Fe, $\mathrm{Zn}$ and $\mathrm{Se}$ ), and some vitamins. All the essential amino acids are present in G. lucidum. Proteins are particularly rich in leucine and lysine (Cör et al., 2018; Khatian and Aslam, 2018). In another study, G. lucidum was considered to be useful as source of protein $(7-8 \%)$, carbohydrates $(3-5 \%)$, crude fat $(3-5 \%)$, crude fiber $(59 \%)$, ash $(1.8 \%)$, and other trace elements on dry weight basis (Mau et al., 2001). G. lucidum was reported to have 16 amino acids, among them, glutamic acid, aspartic acid, glycine, and alanine showed 
the highest relative abundance, whereas methionine showed the least (Wang et al., 2002). Tokul-Olmez et al. (2018) concluded that the host tree affected the fatty acid constituents and fatty acid concentration regarding higher palmitic acid and oleic acid among others in wild $G$. lucidum samples where the negligible effect was observed for the altitude. G. lucidum also contains a higher amount of chitin which makes it hard to chew and digest (WachtelGalor et al., 2011; Sudheer et al., 2018).

G. lucidum has a high proportion of polyunsaturated fatty acids (PUFA) (Sanodiya et al., 2009; Wachtel-Galor et al., 2011). Stojkovic et al. (2014) compared the nutritional composition of wild G. lucidum from Serbia and cultivated G. lucidum from China. As a result, the amounts of proteins (11.34 g/100 g dw), total tocopherols (104.75 $\mu \mathrm{g} / 100 \mathrm{~g} \mathrm{dw})$, and sugars $(9.14 \mathrm{~g} / 100 \mathrm{~g} \mathrm{dw})$ were higher in samples from Serbia while the amounts of organic acids $(4.57 \mathrm{~g} / 100 \mathrm{~g} \mathrm{dw})$, PUFA (42.42\%), ergosterol (766.18 mg/100 g dw), and total phenolic compounds $(3.30 \mathrm{mg} / 100 \mathrm{~g} \mathrm{dw})$ were higher in the samples from China. Yildiz et al. (2015) reported that protocatechuic acid, $p$-hydroxybenzoic acid, catechin, chlorogenic acid, vanillic acid, syringic acid, $p$-coumaric acid, rutin, and $t$-cinnamic acid were determined in high amounts as the major phenolic compounds in wild $G$. lucidum. Turfan et al. (2018) reported total soluble protein, total free amino acid, total phenolics, total flavonoids, glucose, fructose, sucrose, and total soluble carbohydrates contents of cultivated $G$. lucidum as 83.68, 3.14, 55.47, $30.66,37.55,1.09,0.26$ and $245.42 \mathrm{mg} / \mathrm{g}$, respectively. In addition, $\mathrm{Ca}, \mathrm{Fe}, \mathrm{K}, \mathrm{Mg}, \mathrm{Na}, \mathrm{P}$ and Se amounts were 246.21, 109.42, 1345.07, 16.19, 6.46, 1662.06 and $2.47 \mathrm{mg} / \mathrm{kg}$, respectively. Approximately 400 different bioactive compounds were reported in the fruiting bodies, mycelia, and spores of G. lucidum in various researches (Xu et al., 2011 a, b; Boh, 2013; Cör et al., 2018; Hapuarachchi et al., 2016a, 2018; Sudheer et al., 2018; Sharma et al., 2019; Zhao et al., 2019). According to Karthikeyan et al. (2009), Pekşen and Yakupoğlu (2009), and Turfan et al. (2016), the differences in the chemical composition of wild and cultivated $G$. lucidum extracts were attributed to different sites of collection, quality of the strain, origin, cultivation conditions, stages of harvesting, and extraction processes of cultivated ones.

G. lucidum has been considered to be a therapeutic fungal biofactory for bioactive compounds which can reduce the lethal effects of cancer. All parts of G. lucidum were indicated to contain polysaccharides, triterpenoids, and peptidoglycans and polyphenols as anticancer compounds (Paterson, 2006; Wachtel-Galor et al., 2011; Sudheer et al., 2018; Sharma et al., 2019). Anti-angiogenic polysaccharides (mainly $\alpha-1,3, \beta-1,3$ and $\beta-1,6-D$-glucans, Ganoderan) and cytotoxic, antitumor, antimetastatic triterpenes/triterpenoids (mainly ganodermic acids, ganodermic alcohols and lucidenic acids) of $G$. lucidum are main bioactive components to inhibit cancer development via suppressing cancer cells proliferation, invasion, and metastasis, as well as promoting cancer cells apoptosis. They work by different molecular mechanisms and signaling pathways in different cancers. All of the G. lucidum polysaccharides contain heteropolymer structures with glucose as the major sugar component and are responsible for the structural analysis of anti-tumor polysaccharides to strengthen the immune system rather than direct cytocidal effects. In G. lucidum, the chemical structure of the triterpenes is based on lanostane (mainly C30), a metabolite of lanosterol, and its biosynthesis is based on cyclization of squalene and extract of G. lucidum tastes bitter due to the presence of these triterpenoids. Triterpenoids of G. lucidum have been reported to have many enzyme inhibitory activities that are useful as chemotherapeutic agents. Moreover, G. lucidum polysaccharides and triterpenes have immunomodulating, immunostimulating, anti-inflammatory, anti-oxidant, and radio-protective activities related to cancer (Dinesh Babu and Subhasree, 2008; Wachtel-Galor et al., 2011; Xu et al., 2011b; Wiater et al., 2012; Boh, 2013; Kao et al., 2013; Zhang et al., 2007; Zhou et al., 2012; Cheng and Sliva, 2015; Duru and Tel Çayan, 2015; Ferreira et al., 2015; Valverde et al., 2015; Cao et al., 2018; Cör et al., 2018; Sohretoglu and Huang, 2018; Sudheer et al., 2018; Ye, 2018). Liu et al. (2007) isolated a compound (Ganoderol B) from the fruiting body of G. lucidum and showed its anti-androgen effect against prostate cancer. However, the polysaccharides and triterpene contents change according to the parts and growing stages of the mushroom. Also, branching conformation and solubility characteristics were reported to affect the antitumorigenic properties of these polysaccharides (Wachtel-Galor et al., 2011; Nakagawa et al., 2018). Anticancer effects of polysaccharides, terpenes and proteins of G. lucidum existed the immunomodulatory effect including activation of cytotoxic T or B lymphocytes, macrophages, natural killer (NK) cells, dendritic cells, and other immune cells along with their secretory products like tumor necrosis factor- $\alpha$ (TNF- $\alpha$ ), reactive nitrogen, oxygen intermediates, and interleukins (IL-1, IL-2, IL-3, IL-6); antiproliferative and pro-apoptotic effects on tumor cells via the promotion of the in vitro proliferation of undifferentiated spleen cells, and the production of cytokines and antibodies. Within the anticancer and antimetastatic activities, NF- $\kappa \mathrm{B}$ and MAPK, the most comprehensively investigated major pathways were shown to be activated and released cytokines that subsequently inhibited the growth of tumor cells. In addition, TLR-4 was an effective receptor involved in the host defense mechanism of the immune response to polysaccharides (Deepalakshmi and Mirunalini, 2011; Boh, 2013; Kao et al., 2013; Cheng and Sliva, 2015; Cao et al., 2018; Sohretoglu and Huang, 2018). In addition, other active compounds from $G$. lucidum have been described, such as ergostane sterols and ergosterol (provitamin $\mathrm{D}_{2}$; range, 189.1-1453.3 $\mu \mathrm{g} / \mathrm{g}$ ), nucleosides, and nucleotides (T, U, I, A and $\mathrm{G} ; 303-1217 \mu \mathrm{g} / \mathrm{g}$ in the mushroom cap and $22-334 \mu \mathrm{g} / \mathrm{g}$ in the stem) with platelet aggregation effect, fatty acids (palmitic acid, linoleic acid, oleic acid, stearic acid) with potential effect of tumour cell proliferation inhibition, and fatty acids (nonadecanoic acid, heptadecanoic acid, stearic acid, palmitic acid) with inhibitory activity, alkaloids (choline, betaine, saponin, flavonoid, tannin), vitamins (riboflavin, vitamin C), essential and nonessential minerals (selenium (Se) up to $72 \mu \mathrm{g} / \mathrm{g} \mathrm{dw}$; germanium (Ge) $489 \mu \mathrm{g} / \mathrm{g}$, $\mathrm{Cu}, \mathrm{Zn}, \mathrm{P})$, hydrocarbons, monoterpenes, and sesquiterpenes (Paterson, 2006; Wachtel-Galor et al., 2011; Boh, 2013; Cör et al., 2018; Sudheer et al., 2018). G. lucidum can biotransform $20-30 \%$ of inorganic Se present in the growth 
substrate into Se-containing proteins and organic Ge is not an essential element at low doses but it has been credited with immunopotentiating, antitumor, antioxidant, and antimutagenic activities (Wachtel-Galor et al., 2011; Sudheer et al., 2018). Lu et al. (2016) determined that water extracts of cultured mycelium from various species $(A$. blazei, A. cinnamomea, G. lucidum and $H$. sinensis) enhanced NK cell cytotoxic activity against cancer cells and G. lucidum might produce both stimulatory and inhibitory effects on immune cells, depending on the conditions. Boh (2013) emphasized that the anticancer activity of G. lucidum might be attributed to at least five groups of mechanisms: (1) activation/modulation of the immune response of the host, (2) direct cytotoxicity to cancer cells, (3) inhibition of tumorinduced angiogenesis, (4) inhibition of cancer cells proliferation and invasive metastasis behaviour, and (5) carcinogens deactivation with protection of cells.

On the other hand, a reversible and a highly specific competitive $\alpha$-glucosidase inhibitor known as SKG-3 was also found in G. lucidum with an $\mathrm{IC}_{50}$ of $4.6 \mu \mathrm{g} / \mathrm{mL}$ (Kim and Nho, 2004). In an animal study (diabetic rats), nonenzymic and enzymic antioxidant levels increased and lipid peroxidation levels decreased with $G$. lucidum treatment (Jia et al., 2009). Furthermore, the alcoholic extract of $G$. lucidum was found to minimize oxidative stress, restore cellular viability, and aid in maintaining cellular redox balance under hypoxia (Kirar et al., 2017). Stojkovic et al. (2014) reported that samples from China revealed slightly better results for lipid peroxidation inhibition $\left(\mathrm{EC}_{50} 0.23 \mathrm{mg} / \mathrm{mL}\right.$ ), while the samples from Serbia exhibited inhibitory potential against human breast $\left(\mathrm{GI}_{50} 309.66 \mu \mathrm{g} / \mathrm{mL}\right)$ and cervical carcinoma $\left(\mathrm{GI}_{50} 311.19\right.$ $\mu \mathrm{g} / \mathrm{mL}$ ) cell lines. No cytotoxicity in non-tumour liver primary cell culture was observed for the different samples. Bal (2019) detected total antioxidant status (5.509 $\mathrm{mmol} / \mathrm{L})$, total oxidant status $(10.177 \mu \mathrm{mol} / \mathrm{L})$, and oxidative stress index $(0.185 \mu \mathrm{mol} / \mathrm{L})$. It was concluded that $G$. lucidum was a natural antioxidant and antimicrobial agent. Table 1 shows the common pharmacological effects of major bio compounds and various extracts of $G$. lucidum.

Table 1 Common pharmacological effects of G. lucidum major bioctive compounds/various extracts

\begin{tabular}{|c|c|c|}
\hline Pharmacological effects & Major bioactive compounds/various extracts & References \\
\hline \multirow{3}{*}{$\begin{array}{l}\text { Anti-cancer, (anti- } \\
\text { angiogenic, cytotoxic, } \\
\text { anti-tumour, anti- } \\
\text { metastatic) }\end{array}$} & $\begin{array}{l}\text { Polysaccharides }(1 \rightarrow 3,1 \rightarrow 4 \text {, and } 1 \rightarrow 6 \text {-linked } \beta \text { and } \alpha \text {-D } \\
\text { (or L)-glucans) }\end{array}$ & $\begin{array}{l}\text { Wachtel-Galor et al., 2011; } \\
\text { Ferreira et al., } 2015\end{array}$ \\
\hline & Glycopeptides and peptidoglycans & $\begin{array}{l}\text { Wachtel-Galor et al., 2011; } \\
\text { Ferreira et al., 2015; Cör et } \\
\text { al., 2018; Hapuarachchi et al., } \\
\text { 2018; Sudheer et al., } 2018\end{array}$ \\
\hline & $\begin{array}{l}\text { Triterpenoids (ganoderic, ganodermic, ganolucidic acids, } \\
\text { ganoderals, ganoderiols, lucidumol, lucialdehyde, } \\
\text { lucidenic acids) }\end{array}$ & $\begin{array}{l}\text { Yuen and Gohel, 2005; } \\
\text { Wachtel-Galor et al., 2011; } \\
\text { Boh, 2013; Duru and Tel } \\
\text { Çayan, } 2015\end{array}$ \\
\hline $\begin{array}{l}\text { Immunomodulatory, } \\
\text { anti-cancer and anti- } \\
\text { tumour }\end{array}$ & $\begin{array}{l}\text { Protein Ling Zhi-8 (LZ-8), lectin, ribosome inactivating } \\
\text { proteins, antimicrobial proteins, glycopeptides/glycoproteins, } \\
\text { peptidoglycans/ proteoglycans, ganodermin A, ribonucleases, } \\
\text { proteinases, metalloproteases, laccases }\end{array}$ & $\begin{array}{l}\text { Zhou et al., 2007, 2012; } \\
\text { Wachtel-Galor et al., 2011; } \\
\text { Xu et al., 2011a; Boh, 2013; } \\
\text { Cao et al., 2018; Sudheer et } \\
\text { al., } 2018\end{array}$ \\
\hline Antidiabetic & $\begin{array}{l}\text { Polysaccharides, proteoglycans, proteins (LZ-8) and } \\
\text { triterpenoids }\end{array}$ & Ma et al., 2015 \\
\hline Anti-inflammatory & Ganoderic acids T-Q and lucideinic acids A, D2, E2, and P & Sliva et al., 2003 \\
\hline Antioxidant & $\begin{array}{l}\text { Triterpenes, polysaccharides, polysaccharide-peptide } \\
\text { complex and phenolic component; Methanolic extracts; } \\
\text { Phenolic and polysaccharide extracts }\end{array}$ & $\begin{array}{l}\text { Mehta, 2014; Kana et al., } \\
\text { 2015; Y1ld1z et al., 2015; } \\
\text { Kumari et al., 2016; Heleno et } \\
\text { al., } 2012\end{array}$ \\
\hline $\begin{array}{l}\text { Cardiovascular } \\
\text { problems }\end{array}$ & Polysaccharides (Ganopoly) & Gao et al., 2004 \\
\hline Antiviral & $\begin{array}{l}\text { Triterpenoids against Enterovirus 71; Ganoderic acid } \\
\text { derivatives against } \mathrm{H} 5 \mathrm{~N} 1 \text { and } \mathrm{H} 1 \mathrm{~N} 1 \text { influenza; } \\
\text { Ganoderiol F, ganodermanontriol against HIV-1 }\end{array}$ & $\begin{array}{l}\text { Zhang et al., 2014; Zhu et al., } \\
\text { 2015; Bishop et al., } 2015\end{array}$ \\
\hline \multirow{2}{*}{ Antimicrobial } & $\begin{array}{l}\text { Polysaccharides; Triterpenoids (ganoderic acids, } \\
\text { ganodermin, ganoderic acid A, ganodermadiol, } \\
\text { ganodermanondiol, lucidumol B, ganodermanontriol, } \\
\text { ganoderic acid B, ganolucidic acid B) }\end{array}$ & $\begin{array}{l}\text { Mehta, 2014; Cör et al., 2018; } \\
\text { Hapuarachchi et al., } 2018\end{array}$ \\
\hline & $\begin{array}{l}\text { Aqueous and methanolic extracts; methanolic extracts; } \\
\mathrm{MeOH} \text { and DCM extracts; Triterpenes, ganomycein, and } \\
\text { other aqueous extracts }\end{array}$ & $\begin{array}{c}\text { Sudheer et al., 2018; } \\
\text { Sanodiya et al., 2009; } \\
\text { Stojkovic et al., 2014; Bal, } \\
\text { 2019; Hleba et al., 2014 }\end{array}$ \\
\hline
\end{tabular}


Ganoderma presents three characteristics for prevention or treatment of diseases: (1) it does not produce any toxicity or side effects; (2) it does not act on a specific organ and (3) it promotes the improvement of normalization of the organ function (Valverde et al., 2015). Because of its biologically active compounds, modern pharmacological tests have generally demonstrated some important pharmacological effects of G. lucidum such as anxiolytic, anti-angiogenic, antidepressant, antitumor, anticancer, cytotoxic, antimetastatic, hypoglycemic, antihyperlipidemic, antihistaminic, anti-obesity, anti-inflammatory, antihypertensive, anti-allergic, antihistaminic, antiradiation, hepatoprotective, chemopreventive, immunomodulating, anti-anemic, anti-androgenic, antimutagenic, antioxidant, antiparasitic, antihepatitis, anti-aging, anti-androgenic, anti-arthritic, antidiabetic, antibacterial, antiviral anti-HIV, prebiotic, neuro-protective, dermatocosmetic, acetylcholinesterase inhibitory, acute gastric ulcer mucoprotective, cytokine production inductive, inhibition of lipid peroxidation/oxidative DNA damage, maintenance of gut health, stimulation of probiotic, urinary tract in men, atherosclerosis, liver and kidney protective, cardiovascular potential activities in addition to other activities against such as fibromyalgia in women, platelet aggregation, and topical sarcoidosis (Zhou et al., 2012; Sanodiya et al., 2009; Deepalakshmi and Mirunalini, 2011; Wachtel-Galor et al., 2011; Boh, 2013; Bishop et al., 2015; Duru and Tel Çayan, 2015; Ferreira et al., 2015; Valverde et al., 2015; Cör et al., 2018; Hapuarachchi et al., 2016a, b, 2017, 2018; Khatian and Aslam, 2018; Sudheer et al., 2018; Ye, 2018; Sharma et al., 2019; Zhao et al., 2019). Moreover, the effects of $G$. lucidum and its extracts such as polysaccharides, triterpenes, and acids on the protection of neurological diseases as abnormal neurogenesis, epilepsy, spinal cord injury, neural tube defects, neurasthenia, depression, and Alzheimer's, Parkinson's, and cerebrovascular diseases, have been previously established (Ye, 2018; Zhao et al., 2019).

\section{Clinical Trials, Side Effects and Toxicity of G. lucidum}

In addition to various in vitro and in vivo studies previously conducted on therapeutic and medicinal properties of G. lucidum (Gao et al., 2005; Wachtel-Galor et al., 2011; Boh, 2013; Hapuarachchi et al., 2016a, b, 2017, 2018; Cao et al., 2018; Cör et al., 2018; Khatian and Aslam, 2018; Sudheer et al., 2018; Zeng et al., 2018), the pharmacological effectiveness of $G$. lucidum and its extracts, drugs, spores, tablets, capsules etc. have confirmed and proved by clinical trials, mostly in Asian countries, such as China, Japan, and Korea in addition to USA and Malaysia (Wachtel-Galor et al., 2011; Boh, 2013; Nahata, 2013; Cheng and Sliva, 2015; Hapuarachchi et al., 2016a, b; Cao et al., 2018; Cör et al., 2018; Sohretoglu and Huang, 2018; Sudheer et al., 2018; Zeng et al., 2018; Sharma et al., 2019; Zhao et al., 2019). However, due to the difficulty in obtaining large amounts of the pure triterpenoids and polysaccharides, double-blind clinical data of the active components are limited. No natural products or extracts from Ganoderma have been reported to enter clinical trial (Hapuarachchi et al., 2017). Although the data from recent in vitro and in vivo studies demonstrate promising anti-cancer effects, a need was identified for further (1) isolation and purification of compounds, with deeper understanding of their individual and synergistic pharmacological effects, (2) molecular level studies of the antitumor and immuno-supportive mechanisms, (3) well designed in vivo tests and controlled clinical studies, and (4) standardisation and quality control for G. lucidum strains, cultivation processes, extracts, and commercial formulations (Boh, 2013). With regard to the effective components, fungal immunomodulatory proteins (FIPs) and polysaccharides were dominant of which LZ-8 and polysaccharides from $G$. lucidum were the mostly researched (Cao et al., 2018). Although the results of human studies provided some evidence that the antitumor effects of G. lucidum were mediated via effects on the immune system, all studies were conducted by the same research group and that other direct antitumor effects of $G$. lucidum had not been studied on humans in vivo, yet (Wachtel-Galor et al., 2011). Hapuarachchi et al. (2016b) concluded that most of the clinical trials were successful with G. lucidum preparation, however factors like small sample size, lack of a placebo control group, lack of information regarding long term treatment of the drug, age, patient's gender and side effects, standard method of extraction of G. lucidum, standard dosage, and the number of patients treated undermine the validity of the results. For this reason, Hapuarachchi et al. (2016a) emphasized that the efficiency of G. lucidum in clinical treatments could be proven by systematic translational research programs using only standardized, preclinically evaluated and biologically active G. lucidum extracts in alternative treatments. Hence, studies on G. lucidum should focus on improving methods and further clinical research on human subjects should be performed with more scientific reproducibility. Boh (2013) listed the examples of published medical investigations with $G$. lucidum preparations including case studies and clinical trials with different dosages. The researcher emphasized that methodologies in the described cases were not often scientifically rigorous and the results were not statistically relevant. In addition, the experimental settings varied a lot and systematically designed double-blind placebo-controlled randomized trials. According to Cheng and Sliva (2015), complete safety analysis on G. lucidum was necessary. Although the efficacy of G. lucidum in cancer patients was reported, clinical observations were needed and it should be used with caution in patients when combined with chemotherapy. Moreover, although there were generally no serious side effects of using G. lucidum (Boh, 2013; Cao et al., 2018), patients should be monitored for liver toxicity (Yuen et al., 2004), chronic watery diarrhea (Wanachiwanawin et al., 2006), and fatal fulminant hepatitis (Wanmuang et al., 2007) that were previously reported as adverse side effects of commercial G. lucidum products consumption. In addition, Gill and Rieder (2008) reported that exposure of cells to higher levels of G. lucidum extracts caused significant reduction in cell viability in some cell lines. A few human sensitization to G. lucidum antigen and allergy and skin reactivity to spore and whole body extracts of G. lucidum cases were also previously reported. Patients with hypoglycemia, gastric ulcers, and active gastrointestinal bleeding, tendency for bleeding, blood disorders like thrombocytopenia, and patients who were on anticoagulants or antiplatelets medication, and under 
treatments for hypertension should be cautious since it lowered the blood sugar level, had anticoagulant effects, an additive effect on clotting factors and prolongation of prothrombin time, and hypotensive properties. G. lucidum was not recommended for breastfeeding and pregnant women since no scientific data was found about effects on lactation (Hapuarachchi et al., 2016b; Sohretoglu and Huang, 2018).

\section{Products of G. lucidum from Traditional Knowledge to Modern Commercial Perspective}

All Traditional Chinese Medicine specialists believe that G. lucidum is the most highlighted one amongst the most powerful available adaptogens (Khatian and Aslam, 2018). The "mushroom of immortality" has been utilized as herbal extract like concoctions of tea and tonics and a remedy in Traditional Chinese Medicine to improve health and longevity for thousands of years, as well as in the treatment of neurasthenia, hypertension, hepatopathy, carcinoma, fatigue, coughing, chronic hepatitis, bronchitis, asthma, insomnia, indigestion, high cholesterol, nephritis, and neurosis in China, Japan, and Korea (Wang et al., 2012b; Khatian and Aslam, 2018; Sudheer et al., 2018). In Asia, Ganoderma has been administered as drugs in the treatment of cancer for centuries since it exhibits anticancer effect alone or in combination with chemotherapy and radiotherapy in addition to reducing the side effects and pain of cancer patients during the treatment via immune system suppression and fatigue (Boh, 2013; Valverde et al., 2015; Sudheer et al., 2018). Jiaogulan (Gynostemm pentaphyllum) is mixed with $G$. lucidum and made "Lingzhi Jiaogulan oral liquid" which helps in relieving palpitation, shortness of breath, and insomnia (Yan, 2015). In vitro and in vivo studies, using combinations of green tea extract and $G$. lucidum have proven its synergistic effects in cancer prevention and treatment (Thyagarajan et al., 2007). In addition, traditional remedies known as "Lingzhi Bao" like China G. lucidum essence have been utilized with an increase by the people (Zhou et al., 2012). There are nearly 200 medicines and compounded medicines containing Ganoderma available within China (Chen et al., 2016). Nowadays, G. lucidum has been recognized as an alternative adjuvant in the prevention and treatment of leukemia, carcinoma, heart disease, hypertension, hepatitis, neurasthenia, and diabetes, as well as an immune system enhancer with health benefits. It can also clean the blood, detoxify and regulate endocrine function and help for promoting longevity and strengthening health (Zhou et al., 2012; Sanodiya et al., 2009; Ye, 2018). More than 100 brands of different products based on G. lucidum can be found in the world market (Lai et al., 2004). Various products such as dried powder and aqueous/ethanol extracts of G. lucidum are prepared from its cultivated fruiting bodies, mycelia, and spore powder and have been commercialized as drugs, dietary supplements, nutraceuticals, functional foods, mycopharmaceuticals, and cosmetology products worldwide (Lai et al., 2004; Zhou et al., 2012; Bishop et al., 2015; Valverde et al., 2015; Hapuarachchi et al., 2018). These include crushed fruiting bodies, fermentation broth, crude extracts, and isolated bioactive constituents in various formulations, which are marketed all over the world in the form of G. lucidum slices, powdered spore solution for injection, pills, tablet, oral liquid, health drink, granule, tincture, bolus; soup, yogurt, black/ green tea, coffee, cocoa powder (Lindequist et al., 2005; Deepalakshmi and Mirunalini, 2011; Bishop et al., 2015; Zhao et al., 2019); spore oils in capsule, soft capsule, cream, hair tonic, and syrup (Wachtel-Galor et al., 2011; Hapuarachchi et al., 2018) in addition to alcoholic beverages (Bishop et al., 2015; Veljovic et al., 2019), herbal and Sanqi wines (Hapuarachchi et al., 2018), tonic liquor $(\mathrm{Xu}, 2001)$, beer, traditional rice wine (Yakju), ginseng $G$. lucidum Sihe liquor and healthy wine of germanium-enriched Ganoderma and Cordyceps (Zhou et al., 2012; Zhao et al., 2019) and ointments, antiseptic creams, and herbal soaps (Sudheer et al., 2018). Over 1,000 Ganoderma health food products were certified by Chinese government (Chen et al. 2016). In addition, G. lucidum could be considered as natural preservatives of food industry (Kana et al. 2015). Functional food studies for emulsion type sausage (Ghobadi et al., 2018), smoked fish sausage (Wannasupchue et al., 2011), yogurt (Li et al., 2011), bread (Chung et al., 2004), and alcoholic beverages (Veljovic et al., 2019) have been also conducted. GanoPoly and Immulink MBG as G. lucidum nutraceuticals are aqueous polysaccharide fractions isolated with patented methods (Bishop et al., 2015). In addition, BreastDefend $^{\mathrm{TM}}$, MycoPhyto ${ }^{\circledR}$ Complex, New Chapter ${ }^{\circledR}$, LifeShield ${ }^{\circledR}$ Immunity, and ReishiMax capsules are examples of marketed products of G. lucidum extracts with or without other mushrooms claiming diverse biological activities (De Silva et al., 2013). Many pharmaceutical, cosmetology, and beauty products made from this mushroom such as day and night cream, whitening cream, anti-aging facial mask, face serum, toothpaste, lotion, and shampoo are available in the markets and demand high price (Taofiq et al., 2016; Wu et al., 2016; Hapuarachchi et al., 2018). Giavasis (2014) reported that, Lentinan, an acidic proteoglucan from $G$. lucidum has been used as antiHIV drug. The annual sale of products derived from $G$. lucidum was estimated to be more than US\$ 2.5 billion in Asian countries, including China, Japan, and South Korea (Li et al. 2013; Bishop et al., 2015). Li et al. (2016) showed that China was the largest producer and exporter with a capacity over 110,000 MT/year of fruiting bodies, slices, and spore powders as most popular products among consumers. Meanwhile, many patented products have emerged which include the preparation of anti-tumor, liver function accelerant, lowering of blood pressure, hypoglycemic activity, lowering of cholesterol levels, treatment of chronic bronchitis, immunomodulator, lysozyme as antibiotic, and shampoo, body shampoo, etc. (Zhou et al., 2012). Boh (2013) established the patent documents on $G$. lucidum spores and dry pulverised mycelia, diverse production and disclosing isolation methods of triterpenes, clinical, in vivo and in vitro tests, immunostimulation and disclosing isolation methods of pharmacologically active polysaccharides, proteins, glycopolysaccharides, glycoproteins, and peptidoglycans isolated from $G$. lucidum, preparation methods of crude extracts from $G$. lucidum with complex compositions and anticancer pharmaceutical formulations containing $G$. lucidum. 
The simplest manufacturing type consists of intact fruiting bodies dried and ground to powder and then processed to capsule or tablet form. Other "nonextracted" products are prepared from the following three sources: (1) dried and powdered mycelia harvested from submerged liquid cultures grown in fermentation tanks; (2) dried and powdered combinations of substrate, mycelia, and mushroom primordia, following inoculation and incubation of a semisolid medium with fungal mycelia; and (3) intact fungal spores or spores that have been broken by mechanical means or have had the spore walls removed (Wachtel-Galor et al., 2011). Generally, for other products preparing with biocompounds "extracted", most polysaccharides are extracted by using hot water-extract-alcohol or waterextract-alkali precipitation methods. Novel technologies using ultrasound, microwave, and enzymatic methods have recently been developed to increase the yield in shorter extraction times. The extracted polysaccharides are further isolated and purified by fractional precipitation, acidic precipitation, ion exchange chromatography, gel filtration, affinity chromatography, and TLC. Triterpenes are usually extracted by using organic solvents such as methanol, ethanol, acetone, chloroform, ether, or a mixture of these solvents followed by different separation methods. Ultrasonic, normal and reverse-phase HPLC, and silica gel column chromatography techniques are currently being used to enhance the rate of extraction of triterpenes by destroying the dense structure in the cells. G. lucidum proteins, peptidoglycans, and glycoproteins are extracted with the processes containing preparative chromatographic techniques, such as gel filtration and ion exchange chromatographies in addition to initial extractions with water or alkaline aqueous solutions (Wachtel-Galor et al., 2011; Boh, 2013; Kao et al., 2013; Ferreira et al., 2015; Sudheer et al., 2018). Moreover, supercritical $\mathrm{CO}_{2}$ with or without co-solvent, subcritical water, and subcritical petroleum ether were previously used to extract various biocompounds such as ganoderic acids, ganoderic alcohols, $\beta$-glucans, and other polysaccharides, chitins, ergosterol, and fatty acids of G. lucidum (Wachtel-Galor et al., 2011; Boh, 2013; Morales et al., 2018). The use of nanotechnology to administer extracts of $G$. lucidium might also improve the bioavailability of the drugs and effectiveness ( $\mathrm{Li}$ et al., 2010). After extraction of biocompounds, they were evaporated to dryness and tabulated/encapsulated either separately or integrated together in designated proportions. Several other products have been prepared as binary, ternary, or more complex mixtures of powdered G. lucidium and other mushrooms and even with other medicinal herbs (Wachtel-Galor et al., 2011).

However, the amount and percentage of each component could be very diverse in natural and commercial products (Wachtel-Galor et al, 2011; Zhou et al., 2012). Chang and Buswell (2008) randomly selected 11 samples of commercial G. lucidum products purchased in Hong Kong shops and evaluated for the two major active components, triterpenes and polysaccharides. The triterpene content ranged from undetectable to $7.8 \%$ and the polysaccharide content varied from 1.1-15.8\%. Boh (2013) and Zeng et al. (2018) underlined that the major obstacle for the acceptance of natural products, such as G. lucidum, in the doctrines of Western pharmaceutical and medical systems, is the complexity and variability of preparations from natural sources. If complex mixtures were of a standardised high quality and the homogeneity, they could bring significant advantages due to synergistic effects. Paterson (2006) informed that in the United States, the Food and Drug Administration (FDA) does not regulate the marketing of fungal medicinal products. Thus, Wu et al. (2017) evaluated 19 batches of products of G. lucidum herbal/mushroom supplements purchased in the United States based on their bioactive components including triterpenes and polysaccharides by using chromatographic methods and saccharide mapping. The results showed that the measured ingredients of only 5 tested samples $(26.3 \%)$ were in accordance with their labels. Loyd et al. (2018) analyzed 20 manufactured products (e.g., pills, tablets, teas, etc.) and 17 grow your own (GYO) kits labeled as containing $G$. lucidum. They identified the majority $(93 \%)$ of the manufactured reishi products and almost half of the GYO kits as G. lucidum. Their results indicated that the content of these products varied and a better labeling was needed to inform consumers before these products were ingested or marketed as medicine. In addition, some researchers have developed methods to aid with assessment of the bioavailability of various ganoderic acids, while others have studied factors that may influence the bioavailability (Bishop et al., 2015). Although the pharmacokinetics of other fungal polysaccharides were previously evaluated, how to figure out the pharmacodynamics, standardize the quality and perform reliable pharmacokinetic and bioavailability studies of $G$. lucidum polysaccharides remained to be determined (Cheng and Sliva, 2015; Ferreira et al., 2015; Cao et al., 2018; Zeng et al., 2018). In phytotherapeutic approach, a fraction of an active extract or mixture of such fractions might prove better therapeutically, less toxic, and inexpensive compared to pure isolated compounds. However, some problems have been with $G$. lucidum based products because of low reproducibility and poor quality control. Hence, it has been important to develop acceptable and reproducible protocols for manufacturing, extraction and purification processes to ensure high quality, effective, standard, and safe crude G. lucidum products and preparations (Zhou et al., 2012; Nahata, 2013; Hapuarachchi et al., 2018).

\section{Conclusion}

G. lucidum has long been reputed to extend the life span and to increase youthful vigour and vitality. The specific reported attributes of $G$. lucidum include lowering the risk of cancer, heart disease, and infection. These healthpromoting effects are believed to be mediated via the antioxidant, hypotensive, anti-inflammatory, and immunomodulatory properties of the mushroom. The data obtained from the research studies demonstrate the effect of G. lucidum only on the molecular level. Hence, more preclinical and clinical studies are necessary for the validation of this natural product in the prevention and/or therapy of cancer. In addition, G. lucidum-derived products could not meet the demand of consumers and achieve the goals of development not only in the technology content but also in the product quality. Therefore, it is necessary to deeply study the bioactive components from different $G$. lucidum and identify their structures and their affecting mechanisms. Then, based on the chemistry and 
pharmacodynamics research, the new control standard and production process of $G$. lucidum products should be developed in addition to modern cultivation methods. The application of standard pharmaceutical methods to the quality assurance, safety assessment, and efficacy testing of G. lucidum compounds will be the first step in the process of bringing them from the field into the health establishments.

\section{References}

Bal C. 2019. Antioxidant and antimicrobial capacities of Ganoderma lucidum. J Bacteriol Mycol Open Access, 7(1): 5-7.

Bishop KS, Kao CHJ, Xu Y, Glucina MP, Paterson RRM, Ferguson LR. 2015. From 2000 years of Ganoderma lucidum to recent developments in nutraceuticals. Phytochemistry, 114: 56-65.

Boh B. 2013. Ganoderma lucidum: A potential for biotechnological production of anti-cancer and immunomodulatory drugs. Recent Pat Anticancer Drug Discov, 8: 255-287.

Cao Y, Xu X, Liu S, Huang L, Gu J. 2018. Ganoderma: A cancer immunotherapy review. Front Pharmacol, 9: 1217.

Chang ST, Buswell JA. 2008. Safety, quality control and regulational aspects relating to mushroom nutriceuticals. Proc. $6^{\text {th }}$ Intl. Conf. Mushroom Biology and Mushroom Products. GAMU Gmbh, Krefeld, Germany. pp. 188-95.

Chang YS, Lee SS. 2004. Utilisation of macrofungi species in Malaysia. Fungal Divers, 15: 15-22.

Chen RY, Kang J, Du GH. 2016. Construction of the quality control system of Ganoderma products. Edi and Med Mushr, 24(6): 339-344.

Cheng S, Sliva D. 2015. Ganoderma lucidum for cancer treatment: We are close but still not there. Integr Cancer Ther, 14(3): 249-257.

Chung H, Lee J, Kwon O. 2004. Bread properties utilizing extracts of Ganoderma lucidum (GL). J. Korean Soc. Food Sci., Nutr. 33: 1201-1205.

Cör D, Knez Z, Hrnčič MK. 2018. Antitumour, antimicrobial, antioxidant and antiacetylcholinesterase effect of Ganoderma lucidum terpenoids and polysaccharides: A review. Molecules, 23: 649.

De Silva DD, Rapior S, Fons F, Bahkali AH, Hyde KD. 2012. Medicinal mushrooms in supportive cancer therapies: an approach to anti-cancer effects and putative mechanisms of action. Fungal Divers, 55: 1-35.

De Silva DD, Rapior S, Sudarman E, Stadler M, Xu J, Alias SA, Hyde KD. 2013. Bioactive metabolites from macrofungi: ethnopharmacology, biological activities and chemistry. Fung Divers, 62: 1-40.

Deepalakshmi K, Mirunalini S. 2011. Therapeutic properties and current medical usage of medicinal mushroom: Ganoderma lucidum. IJPSR, 2(8): 1922-1929.

Dinesh Babu P, Subhasree RS. 2008. The sacred mushroom "Reishi"-A review. American-Eurasian J Bot, 1(3):107-110.

Duru ME, Tel Çayan G. 2015. Biologically active terpenoids from mushroom origin: A review. Rec. Nat. Prod., 9(4): 456-483.

Ferreira ICFR, Heleno SA, Reis FS, Stojković D, Queiroz MJ, Vasconcelos MH, Soković M, 2015. Chemical features of Ganoderma polysaccharides with antioxidant, antitumor and antimicrobial activities. Phytochemistry, 114: 38-55.

Gao H, Chan E, Zhou F. 2004. Immunomodulating activities of Ganoderma, a mushroom with medicinal properties. Food Rev Int, 20: 123-161.

Gao Y, Gao H, Chan E, Tang W, Xu A, Yang H, Huang M, Lan J, Li X, Duan W, Xu C, Zhou S. 2005. Antitumor activity and underlying mechanisms of Ganopoly, the refined polysaccharides extracted from Ganoderma lucidum, in mice. Immunol Invest, 34: 171-198.
Ghobadi R, Mohammadi R, Chabavizade J, Sami M. 2018. Effect of Ganoderma lucidum powder on oxidative stability, microbial and sensory properties of emulsion type sausage. AdvBiomed Res, 7: 24.

Giavasis I. 2014. Polysaccharides from medicinal mushrooms for potential use as nutraceuticals. In: Benkeblia N (Ed.), Polysaccharides: Natural Fibers in Food and Nutrition, 1st Edition, CRC Press. pp.171-206.

Gill SK, Rieder MJ. 2008. Toxicity of a traditional Chinese medicine, Ganoderma lucidum, in children with cancer. Can J Clin Pharmacol, 15(2): 275-85.

Hapuarachchi KK, Cheng CR, Wen TC, Jeewon R, Kakumyan P. 2017. Mycosphere Essays 20: Therapeutic potential of Ganoderma species: Insights into its use as traditional medicine. Mycosphere, 8(10): 1653-1694.

Hapuarachchi KK, Elkhateeb WA, Karunarathna SC, Cheng CR, Bandara AR, Kakumyan P, Hyde KD, Daba GM, Wen TC. 2018. Current status of global Ganoderma cultivation, products, industry and market. Mycosphere, 9(5): 1025-1052.

Hapuarachchi KK, Wen TC, Jeewon R, Wu XL, Kang JC, Hyde KD. 2016a. Mycosphere Essays 7. Ganoderma lucidum-are the beneficial anti-cancer properties substantiated? Mycosphere, 7(3): 305-332.

Hapuarachchi KK, Wen TC, Jeewon R, Wu XL, Kang JC. 2016 b. Mycosphere Essays 15. Ganoderma lucidum-are the beneficial medical properties substantiated? Mycosphere, 7(6): 687-715.

Heleno SA, Barros L, Martins A, Ferreira ICFR. 2012. Fruiting body spores and in vitro produced mycelium of G. lucidum from Northeast Portugal: a comparative study of the antioxidant potential of phenolic and polysaccharidic extracts. Food Res Int, 46: 135-140.

Hleba L, Vuković, Petrová J, Kačániová M. 2014. Antimicrobial activity of crude methanolic extracts from Ganoderma lucidum and Trametes versicolor. Anim Sci Biotechno, 47: 89-93.

Hyde KD, Bahkali AH, Moslem MA. 2010. Fungi-An unusual source for cosmetics. Fungal Divers, 43: 1-9.

Jia J, Zhang XI, Hu YS, Wu Y, Wang QZ, Li NN, Guo QC, Dong XC. 2009. Evaluation of in vivo antioxidant activities of $G$. lucidum polysaccharides in STZ-diabetic rats. Food Chem, 115: 32-36.

Kana Y, Chen T, Wu Y, Wu J. 2015. Antioxidant activity of polysaccharide extracted from Ganoderma lucidum using response surface methodology. Int J Biol Macromol, 72: 151157.

Kao CHJ, Jesuthasan AC, Bishop KS, Glucina MP, Ferguson LR. 2013. Anti-cancer activities of Ganoderma lucidum: active ingredients and pathways. Functional Foods in Health and Disease, 3(2): 48-65.

Karthikeyan M, Radhika K, Bhaskaran R, Mathiyazhagan S, Velazhahan R. 2009. Rapid detection of Ganoderma lucidum and assessment of inhibition effect of various control measures by immunoassay and PCR. Afr J Biotechnol, 8: 2202-2208.

Khastini RO, Wahyuni I, Saraswati I. 2018. Ethnomycology of bracket fungi in Baduy Tribe Indonesia. Biosaintifika: J Biol Educ, 10(2): 424-432.

Khatian N, Aslam M. 2018. A review of Ganoderma lucidum (Reishi): A miraculous medicinal mushroom. Inventi Rapid: Ethnopharmacology, 2018(4): 1-6.

Kim SD, Nho HJ. 2004. Isolation and characterization of alphaglucosidase inhibitor from the fungus $G$. lucidum. $\mathrm{J}$ Microbiol, 42(3): 223-227.

Kirar V, Nehra S, Mishra J, Rakhee R, Saraswat D, Misra K 2017. Lingzhi or Reishi medicinal mushroom, Ganoderma lucidum (Agaricomycetes), as a cardioprotectant in an oxygendeficient environment. Int J Med Mushrooms, 19(11): 10091021. 
Kumari K, Prakash V, Rana S, Sagar A. 2016. In vitro antioxidant activity of methanolic extract of $G$. lucidum (Curt.) P. Karst. IJASR, 1(5): 51-54.

Lai T, Gao Y, Zhou SF. 2004. Global marketing of medicinal Ling Zhi mushroom Ganoderma lucidum (W.Curt.: Fr.) Lloyd (Aphyllophoromycetideae) products and safety concerns. Int J Med Mush, 6: 189-194.

Li J, Chen W, Li XY, Cheng F. 2011. Ganoderma yogurt and changes in colonies, physical and chemical properties during storage. China Dairy Ind, 5: 18.

Li J, Zhang J, Chen H, Chen X, Lan J, Liu C. 2013. Complete mitochondrial genome of the medicinal mushroom Ganoderma lucidum. Plos One, 8(8): e72038.

Li N, Hu YL, He CX, Hu CJ, Zhou J, Tang GP, Gao JQ. 2010. Preparation, characterisation and anti-tumour activity of Ganoderma lucidum polysaccharide nanoparticles. J Pharm Pharmacol, 62(1): 139-44.

Li S, Dong C, Wen HA, Liu X. 2016. Development of Ling-zhi industry in China-emanated from the artificial cultivation in the Institute of Microbiology, Chinese Academy of Sciences (IMCAS). Mycology, 7: 74-80.

Lindequist U, Niedermeyer TH, Jülich WD. 2005. The pharmacological potential of mushrooms. Evid Based Complement Alternat Med., 2(3): 285-299.

Lisiecka J, Rogalski J, Sobieralski K, Siwulski M, Sokol S, Ohga S. 2015. Mycelium growth and biological efficiency of Ganoderma lucidum on substrate supplemented with different organic additives. J Fac Agr, Kyushu Univ, 60(2): 303-308.

Liu J, Shimizu K, Konishi F, Kumamoto S, Kondo R. 2007. The anti-androgen effect of ganoderol $\mathrm{B}$ isolated from the fruiting body of Ganoderma lucidum. Bioorganic Med Chem, 15(14): 4966-4972.

Loyd AL, Richter BS, Jusino MA, Truong C, Smith ME, Blanchette RA, Smith JA. 2018. Identifying the "Mushroom of Immortality": Assessing the Ganoderma Species Composition in Commercial Reishi Products. Front. Microbiol., 9: 1557.

Lu CC, Hsu YJ, Chang CJ, Lin CS, Martel J, Ojcius DM, Ko YF, Lai HC, Young JD. 2016. Immunomodulatory properties of medicinal mushrooms: differential effects of water and ethanol extracts on NK cell-mediated cytotoxicity. Innate Immun, 22(7): 522-533.

Ma HT, Hsieh JF, Chen ST. 2015. Anti-diabetic effects of Ganoderma lucidum. Phytochemistry, 114: 109-113.

Mau JL, Lin HC, Chen CC. 2001. Non-volatile components of several medicinal mushrooms. Food Res Int, 34(6): 521-526.

Mehta S. 2014. Studies on genetic variability and bioactive molecules production by Ganoderma species. Ph.D. Thesis, Shoolini University of Biotechnology and Management Sciences Bajhol, Solan (HP), India.

Morales D, Ruiz-Rodriguez A, Soler-Rivas C. 2018. The use of pressurized fluid technologies to obtain commercially interesting compounds from edible mushrooms. (Taylor, ed.). Advances in Chemistry Research. New York. Nova Science Publishers, Inc. pp. 1-42.

Nahata A. 2013. Ganoderma lucidum: A potent medicinal mushroom with numerous health benefits. Pharmaceut Anal Acta, 4: e159.

Nakagawa T, Zhu Q, Tamrakar S, Amen Y, Mori Y, Suhara H, Kaneko S, Kawashima H, Okuzono K, Inoue Y, Ohnuki K, Shimizu K. 2018. Changes in content of triterpenoids and polysaccharides in Ganoderma lingzhi at diferent growth stages. J Nat Med, 72: 734-744.

Oyetayo OV. 2011. Medicinal uses of mushrooms in Nigeria: towards full and sustainable exploitation. Afr $\mathrm{J}$ Tradit Complement Altern Med, 8(3): 267-274.

Paterson RRM. 2006. Ganoderma-A therapeutic fungal biofactory. Phytochem, 67: 1985-2001.
Pekşen A, Yakupoğlu G. 2009. Tea waste as a supplement for the cultivation of Ganoderma lucidum. World J of Microbiol and Biotech, 25(4): 611-618.

Perumal K. 2009. Indigenous technology on organic cultivation of Reishi. AMM Murugappa Chettiar Research Centre, 1-12.

Rathore H, Prasad S, Sharma S. 2017. Mushroom nutraceuticals for improved nutrition and better human health: A review. PharmaNutrition, 5: 35-46.

Reis FS, Martins A, Vasconcelos MH, Morales P, Ferreira ICFR. 2017. Functional foods based on extracts or compounds derived from mushrooms. Trends Food Sci Techn., 66: 48-62.

Roy S, Ara M, Jahan A, Das KK, Munshi SK, Noor R. 2015. Artificial cultivation of Ganoderma lucidum (Reishi Medicinal Mushroom) using different sawdusts as substrates. American J BioSci, 3(5): 178-182.

Sanodiya BS, Thakur GS, Baghel RK, Prasad GBKS, Bisen PS. 2009. Ganoderma lucidum: A potent pharmacological macrofungus. Curr Pharm Biotechnol, 10: 717-742.

Sesli E, Denchev CM. 2014. Checklists of the myxomycetes, larger ascomycetes, and larger basidiomycetes in Turkey. 6th edn. Mycotaxon Checklists Online (http://www.mycotaxon.com/resources/checklists/sesliv106-checklist.pdf): 1-136.

Sharma C, Bhardwaj N, Sharma A, Tuli HS, Katyal P, Beniwal V, Gupta GK, Sharma AK. 2019. Bioactive metabolites of Ganoderma lucidum: Factors, mechanism and broad spectrum therapeutic potential. J Herbal Med, xx(x): xx-xx.

Sliva D, Sedlak M, Slivova V, Valachovicova T, Lloyd FP Jr, Ho NW. 2003. Biologic activity of spores and dried powder from Ganoderma lucidum for the inhibition of highly invasive human breast and prostate cancer cells. J Altern Complement Med, 9: 491-497.

Sohretoglu D, Huang S. 2018. Ganoderma lucidum polysaccharides as an anti-cancer agent. Anticancer Agents Med Chem, 18: 667-674.

Stojkovic DS, Barros L, Calhelha RC, Glamočlija J, Ćirić A, Van Griensven LJLD, Soković M, Ferreira ICFR. 2014. A detailed comparative study between chemical and bioactive properties of Ganoderma lucidum from different origins. Int J Food Sci Nutr, 65(1): 42-47.

Sudheer S, Alzorqi I, Manickam S, Ali A. 2018. Bioactive compounds of the wonder medicinal mushroom "Ganoderma lucidum". (Mérillon, Ramawat, eds.). Bioactive Molecules in Food, Reference Series in Phytochemistry. Switzerland. Springer International Publishing AG. 31 p. Online ISBN: 978-3-319-54528-8.

Taofiq O, González-Paramás AM, Martins A, Barreiro MF, Ferreira ICFR. 2016. Mushrooms extracts and compounds in cosmetics, cosmeceuticals and nutricosmetics-A review. Ind Crop Prod, 90: 38-48.

Thyagarajan A, Zhu J, Sliva D. 2007. Combined effect of green tea and Ganoderma lucidum on invasive behavior of breast cancer cells. Int J Oncol, 30(4): 963-9.

Tibuhwa, DD. 2018. Edible and medicinal mushrooms sold at traditional markets in Tanzania. Res J For, 12: 1-14.

Tokul-Olmez O, Kaplaner E, Ozturk M, Ullah Z, Duru ME. 2018. Fatty acid profile of four Ganoderma species collected from various host trees with chemometric approach. Biochem Sys and Ecol, 78: 91-97.

Turfan N, Karadeniz M, Ünal S. 2016. Doğadan toplanan ve portakal kütügünde yetiştirilen Ganoderma lucidum (Curtis.) P. Karst mantar türünün bazı kimyasal içeriklerinin karşılaştırılması. Turkish JAF Sci Technol, 4(3): 158-162.

Turfan N, Pekşen A, Kibar B, Ünal S. 2018. Determination of nutritional and bioactive properties in some selected wild growing and cultivated mushrooms from Turkey. Acta Sci Pol Hortorum Cultus, 17(3): 57-72.

Valverde ME, Hernández-Pérez T, Paredes-López O. 2015. Edible mushrooms: Improving human health and promoting quality life. Int J Microbiol, 2015: 1-14. 
Veljović S, Nikićević N, Nikšić M. 2019. Medicinal fungus Ganoderma lucidum as raw material for alcohol beverage production. (Grumezescu and Holban, eds.). Alcoholic Beverages. Volume 7: The Science of Beverages. Elsevier / Woodhead Publish. pp. 161-197.

Wachtel-Galor S, Yuen J, Buswell JA, Benzie IFF. 2011 Ganoderma lucidum (Lingzhi or Reishi): A medicinal mushroom. (Benzie and Wachtel-Galor, eds.). Herbal Medicine, 2nd edition. Boca Raton (FL). CRC Press/Taylor\&Francis. 53 p. ISBN-13: 978-1-4398-0713-2.

Wanachiwanawin D, Piankijagum A, Chaiprasert A, Lertlaituan P, Tungtrongchitr A, Chinabutr P. 2006. Ganoderma lucidum: a cause of pseudoparasitosis. Southeast Asian J Trop Med Public Health, 37: 1099-102.

Wang JL, Gu T, Zhong JJ. 2012a. Enhanced recovery of antitumor Ganoderic Acid $\mathrm{T}$ from Ganoderma lucidum mycelia by novel chemical conversion strategy. Biotechnol Bioeng, 109(3): 754-762.

Wang XC, Xi RJ, Li Y, Wang DM, Yao YJ. 2012b. The species identity of the widely cultivated Ganoderma, 'G. lucidum' (Ling-zhi), in China. PLoS One, 7(7): e40857.

Wang YY, Chen ST, Lin CC, Wong CH, Lin CH. 2002. Studies on the immunomodulation and antitumor activities of $G$. lucidum (Reishi) polysaccharides: functional and proteomic analysis of fucose-containing glycoprotein fraction responsible for the activities. Bioorg Med Chem, 10: 10571062.

Wanmuang H, Leopairut J, Kositchaiwat C, Wananukul W, Bunyaratvej S. 2007. Fatal fulminant hepatitis associated with Ganoderma lucidum (Lingzhi) mushroom powder. J Med Assoc Thai, 90: 179-181.

Wannasupchue W, Siriamornpun S, Huaisan K, Huaisan J, Meeso N. 2011. Effect of adding Ling-zhi (Ganoderma lucidum) on oxidative stability, textural and sensory properties of smoked fish sausage. Thai J Agric Sci, 5: 505-12.

Wiater A, Paduch R, Choma A, Pleszczyn'ska M, Siwulski M, Dominik J, Janusze G, Tomczyk M, Szczodrak J. 2012. Biological study on carboxymethylated $(1 \rightarrow 3)-\alpha-D$-glucans from fruiting bodies of Ganoderma lucidum. Int $\mathrm{J}$ Biol Macromol, 51: 1014-1023.

Wu GS, Guo JJ, Bao JL, Li XW. 2013. Anti-cancer properties of triterpenoids isolated from Ganoderma lucidum - A review. Expert Opin Investig Drugs, 22: 981-992.

Wu Y, Choi MH, Li J, Yang H, Shin HJ. 2016. Mushroom cosmetics: The present and future. Cosmetics, 3(3): 22.

Wu, DT, Deng Y, Chen LX, Zhao J, Bzhelyansky A, Li SP. 2017. Evaluation on quality consistency of Ganoderma lucidum dietary supplements collected in the United States. Sci. Rep. 7: 7792 .

Xu X, Yan H, Chen J, Zhang X. 2011a. Bioactive proteins from mushrooms. Biotechnol Adv, 29(6): 667-674.

Xu Y. 2001. Perspectives on the 21st century development of functional foods: Bridging Chinese medicated diet and functional foods. Int J Food Sci Technol, 36: 229-242.
Xu Z, Chen X, Zhong Z, Cheny L, Wang Y. 2011b. Ganoderma lucidum polysaccharides: immunomodulation and potential anti-tumor activities. The Amer J Chine Medic, 39: 15-27.

Yan L. 2015. Gynostemma pentaphyllum (Thunb.) Makino (Jiaogulan, Five leaf Gynostemma). In: Liu Y, Wang Z, Zhang J. (Eds) Dietary Chinese Herbs Chemistry: Pharmacology and Clinical Evidence. Springer, London pp. 615-622.

Ye H. 2018. Healthy benefits of Ganoderma lucidum as herb medicinal mushroom. CPQ Nutrition, 1(5): 01-07.

Yıldız O, Can Z, Laghari AQ, Şahin H, Malkoç M. 2015. Wild edible mushrooms as a natural source of phenolics and antioxidants. J Food Biochem, 39: 148-154.

Yuen MF, Ip P, Ng WK, Lai CL. 2004. Hepatotoxicity due to a formulation of Ganoderma lucidum (lingzhi). J Hepatol, 41: 685-90.

Yuen WMJ, Gohel MDI. 2005. Anti-cancer effects of Ganoderma lucidum: A review of scientific evidence. Nutr Cancer, 53: 11-17.

Zeng P, Guo Z, Zeng X, Hao C, Zhang Y, Zhang M, Liu Y, Li H, Li J, Zhang L. 2018. Chemical, biochemical, preclinical and clinical studies of Ganoderma lucidum polysaccharide as an approved drug for treating myopathy and other diseases in China. J Cell Mol Med, 22: 3278-3297.

Zhang M, Cui SW, Cheung PCK, Wang Q. 2007. Antitumor polysaccharides from mushrooms: a review on their isolation process, structural characteristics and antitumor activity. Trends Food Sci Technol, 18(1): 4-19.

Zhang W, Tao J, Yang X, Yang Z, Zhang L, Liu H, Wu K, Wu J. 2014. Antiviral effects of two Ganoderma lucidum triterpenoids against Enterovirus 71 infection. Biochem Biophys Res Commun, 449(3): 307-12.

Zhao C, Zhang C, Xing Z, Ahmad Z, Li J-S, Chang M-W. 2019. Pharmacological effects of natural Ganoderma and its extracts on neurological diseases: A comprehensive review. Int J Biol Macromol, 121: 1160-1178.

Zhou XW, Lin J, Li QZ, Yin YZ, Sun XF, Tang KX. 2007. Study progress on bioactive proteins from Ganoderma spp. Nat Prod Res Develop, 19: 916-924.

Zhou XW, Su KQ, Zhang YM. 2012. Applied modern biotechnology for cultivation of Ganoderma and development of their products. Appl Microbiol Biotechnol, 93: 941-963.

Zhu Q, Bang TH, Ohnuki K, Sawai T, Sawai K, Shimizu K. 2015. Inhibition of neuraminidase by Ganoderma triterpenoids and implications for neuraminidase inhibitor design. Sci Rep, 5: 13194.

Zhu XL, Chen AF, Lin ZB. 2007. Ganoderma lucidum polysaccharides enhance the function of immunological effector cells in immunosuppressed mice. J Ethnopharmacol, 111: 219-226. 